\title{
Kombinasi Plyometric Training Dengan Mobilization With Movement Lebih Baik Dibanding Kombinasi Plyometric Training Dengan Strain Counter Strain Dalam Meningkatkan Keseimbangan Dan Range Of Motion Ankle Joint Pada Kasus Chronic Ankle Instability Di Klinik Barito Farma
}

\author{
Arfian Hamzah ${ }^{1}$, Enny Fauziah ${ }^{1}$, Mar'atus Sa'diah ${ }^{1}$ \\ ${ }^{1}$ Program Studi DIII Fisioterapi Politeknik Unggulan Kalimantan, Banjarmasin \\ email: arfianhamzah42@gmail.com
}

Tanggal Submisi: 15 Maret 2020; Tanggal Penerimaan: 10 Juli 2020

\begin{abstract}
ABSTRAK
Pendahuluan: Chronic Ankle Instability (CAI) merupakan suatu kondisi dimana terjadi ketidakstabilan pergelangan kaki lateral serta gejala sisa seperti nyeri dan keterbatasan luas gerak sendi setelah cedera berulang pada ligament pergelangan kaki lateral.

Tujuan: Untuk membandingkan kombinasi plyometric training dengan Mobilization with Movement (MWM) dan kombinasi plyometric training dengan Strain Counter Strain (SCS) terhadap peningkatan keseimbangan, Range of Motion (ROM), dan fungsional ankle pada kasus CAI.

Metode: Penelitian ini merupakan studi eksperimental dengan rancangan penelitian pre-test and post-test group design. Sampel berjumlah 22 orang yang terdiri dari 11 orang di setiap kelompok. Kelompok 1 diberikan plyometric training dan MWM dan kelompok 2 diberikan plyometric training dan SCS. Latihan diberikan 3x seminggu selama 6 minggu. Teknik pengambilan sampel dengan random sampling. Keseimbangan diukur dengan Star Excursion Balance Test (SEBT), ROM diukur dengan Dorsiflexion Range of Motion (DFROM), fungsional ankle diukur dengan Foot and Ankle Ability Measure (FAAM).

Hasil: Uji Paired sample t-test pada kedua kelompok didapatkan hasil signifikan untuk SEBT, DFROM, FAAM $(p=0,001)$. Hasil sama pada uji Independent sample t-test nilai SEBT dan DFROM $(p=0,001)$, namun nilai FAAM $(p>0,05)$.

Simpulan: Kombinasi plyometric training dengan MWM dan kombinasi plyometric training dengan SCS samasama meningkatkan keseimbangan, ROM, dan fungsional ankle. Namun, untuk meningkatkan keseimbangan dan ROM kombinasi plyometric training dengan MWM lebih baik.

Kata kunci: Mobilization with movement, Strain counter strain, Star excursion balance test, Dorsiflexion range of motion, Chronic ankle instability
\end{abstract}

\section{ABSTRACT}

Introduction: Chronic Ankle Instability (CAI) is a condition in which lateral ankle instability occurs and sequelae such as pain and limited area of joint motion after repeated injuries to the lateral ankle ligament.

Objective: To compare the combination of plyometric training with Mobilization with Movement (MWM) and the combination of plyometric training with Strain Counter Strain (SCS) to increase balance, Range of Motion (ROM), and functional ankle in CAI cases.

Method: This study is an experimental study with a pre-test and post-test group design research design. The sample consisted of 22 people consisting of 11 people in each group. Group 1 was given plyometric training and MWM and group 2 was given plyometric training and SCS. Exercise is given 3 times a week for 6 weeks. The sampling technique was random sampling. Balance is measured by the Star Excursion Balance Test (SEBT), ROM is measured by Dorsiflexion Range of Motion (DFROM), functional ankle is measured by Foot and Ankle Ability Measure (FAAM). 
Results: Paired sample t-test in both groups showed significant results for SEBT, DFROM, FAAM $(p=0.001)$. The results were the same in the Independent sample t-test, the SEBT and DFROM values $(p=0.001)$, but the FAAM value $(\mathrm{p}>0.05)$.

Conclusion: The combination of plyometric training with MWM and the combination of plyometric training with SCS both improve balance, ROM, and functional ankle. However, to improve balance and ROM the combination of plyometric training with MWM is better.

Keywords: Mobilization with movement, Counter strain strain, Star excursion balance test, Dorsiflexion range of motion, Chronic ankle instability

\section{PENDAHULUAN}

Ankle sprain merupakan salah satu cedera yang paling umum dalam olahraga kompetitif maupun olahraga rekreasi. Persentase lateral ankle sprain sebesar $10-30 \%$ dari semua cedera atletik [1]. Ankle sprain mengalami gejala residu seperti ligament laxity, gangguan proprioseptif, penurunan Range of Motion (ROM), pembengkakan berulang, nyeri selama aktivitas, dan ketidakstabilan pergelangan kaki [2]. Cedera berulang pada ankle sprain sebanyak 4 kali lebih berpotensi mengalami Chronic Ankle Instability (CAI) [3]. Gangguan tersebut akan berdampak jangka panjang, sebanyak $72 \%$ orang tidak dapat kembali ke tingkat fungsi semula dan $85 \%$ orang yang didiagnosis CAI mengalami masalah pada ankle joint kontralateral setelah sprain ankle unilateral. Gangguan pada kasus CAI dalam literatur dapat dibagi 2; Functional Instability (FI) dan Mechanical Instability (MI) [4].

FI didefinisikan sebagai perasaan subyektif dari ketidakstabilan dan berhubungan dengan gangguan proprioseptif dan neuromuskuler sementara MI didefinisikan sebagai gangguan kontrol ankle joint akibat lemahnya atau ketidakseimbangan antara otot-otot inversi dan eversi pada ankle joint5. Kondisi panjang tungkai yang tidak sama, arkus kaki rata, kaki varus merupakan faktor pendukung terjadinya cedera karena dalam kondisi ini posisi ligament lateral pada ankle joint akan lebih terulur atau laxity yang menyebabkan sendi menjadi tidak stabil dan meningkatkan resiko cedera berulang
[6]. Perbandingan yang tidak sesuai antara otototot inversi dan eversi ankle joint, rasio kekuatan dorsifleksi dan plantarfleksi yang tidak seimbang, terbatasnya ROM ankle joint, serta bentuk tungkai valgus/varus merupakan faktor intrinsik. Faktor ekstrinsik meliputi kemampuan fisik, jenis lapangan/tanah, dan jenis sepatu yang dipakai [7].

Fisioterapi berperan penting dalam mengembalikan dan menjaga aktivitas fungsional pada seseorang dengan keluhan gangguan keseimbangan pada ankle instability secara optimal dengan cara meningkatkan kekuatan otot, proprioseptif dan kontrol postural. Teknik fisioterapi konvensional seperti kinesiotapping, elektroterapi, termoterapi, telah menunjukkan hasil yang baik dalam mengurangi bengkak dan nyeri yang terkait dengan sprain ankle [8]. Namun demikian penurunan rasa sakit ini, tidak memberikan solusi untuk kemungkinan gejala sisa yang terkait dengan sprain ankle, seperti gangguan proprioseptif, kelemahan otot, keterbatasan ROM. Oleh karena itu, penting untuk melakukan pendekatan integral untuk mengembalikan fungsi and gerak akibat sprain ankle dan untuk menghindari cedera berulang [9]. Hasil penelitian sebelumnya menyatakan bahwa cedera berulang akibat sprain ankle sebesar70\% [10].

Dorsiflexion range of motion (DFROM) sering mengalami gangguan setelah sprain ankle. Terbatasnya DFROM dapat menyebabkan cedera berulang dan itu telah dimasukkan sebagai faktor risiko [11]. DFROM dikaitkan dengan perubahan pada normal arthrokinematik talocrural joint, 
posterior talar glide menjadi terbatas atau perubahan pada posisi talus [2]. Intervensi manual terapi bertujuan untuk memperluas kapsul sendi dengan meregangkannya melalui gerakan aksesoru untuk memulihkan DFROM dengan meningkatkan ekstensibilitas jaringan non-kontraktil [5]. Hasil penelitian Johansen, 2008 mengemukakan bahwa keterbatasan DFROM lebih dipengaruhi oleh subtalar joint daripada tightness dari otot gasctrocnemius ataupun otot soleus [12]. Beberapa teknik manual terapi berdasarkan mobilisasi talocrural joint telah membuktikan keefektifan dalam meningkatkan DFROM dan perbaikan arthrokinematik [13].

Keseimbangan menjadi gangguan pada pasien CAI, terutama pada keseimbangan dinamis [14]. Hal ini disebabkan oleh defisit dalam proprioseptif dan kontrol neuromuskuler pada ankle joint yang mengalami cedera, dan gangguan keseimbangan dianggap sebagai faktor risiko untuk cedera berulang [15]. Mobilisasi sendi menghasilkan dampak positif pada kontrol postural pada pasien CAI [16]. Selain DFROM, gangguan keseimbangan juga perlu perhatian khusus dalam intervensi yang diberikan karena kondisi ini telah diidentifikasi sebagai salah satu faktor penyebab sprain ankle dan faktor penyebab cedera berulang [17].

Strain Counterstrian (SCS) adalah suatu teknik untuk mengoreksi trauma jaringan yang tidak berurutan dengan cara mengembalikannya ke posisi netral secara berurutan berdasarkan prinsip biomekanika, dasar dari teori ini adalah disfungsi neuromuskuloskeletal dimana cedera yang menyebabkan regangan mekanis menyebabkan perubahan muscle spindle pada otot yang terlibat sehingga menyebabkan gangguan proprioseptif [18]. SCS merupakan teknik untuk menurunkan nyeri melalui inhibisi dari aktivitas proprioseptif yang tidak tepat secara terus menerus. Ketika otot berada dalam posisi fine tuning, nyeri dapat berkurang saat palpasi pada trigger point, maka jaringan yang mengalami spasme menjadi rileksasi. SCS memungkinkan muscle spindle untuk menghentikan informasi kontraksi kepada otot sehingga otot dapat rileks [19].

Mobilisasi dengan gerakan (MWM) dijelaskan oleh Mulligan dan dianggap efektif dalam mengurangi nyeri, meningkatkan fungsi, memperbaiki control postural, dan meningkatkan DFROM ankle pada kasus CAI [13]. Teknik ini menggabungkan aplikasi berkelanjutan teknik manual gliding untuk memaksa sendi bergerak dengan bersamaan fisiologis gerak sendi (osteokinematik). Teknik mobilisasi sendi efektif dalam meningkatkan DFROM yang dianggap sebagai faktor predisposisi untuk cedera berulang yang diakibatkan gangguan pada posterior talar glide [20]. Gerakan yang dihasilkan dari teknik MWM menyebabkan pengurangan nyeri melalui aktivasi mekanoreseptor yang menghambat rangsangan nosiseptif melalui mekanisme gate control atau melalui fasilitasi nutrisi cairan synovial, selain itu teknik MWM dapat meningkatkan fungsi sendi karena teknik MWM dapat meningkatkan output sensorik dari reseptor mekanik dalam kapsul ligament pada sendi karena aktivasi neuron motoric gamma yang akan memperbaiki nosiseptif yang mengalami gangguan dan meningkatkan kontrol postural [21].

Plyometric training merupakan latihan yang gerakannya didominasi dengan gerakan melompat, berlari, dan merubah gerakan secara eksplosif. Gerakan dalam latihan ini dapat membantu untuk peningkatan kelincahan karena mengeksploitasi adaptasi stretch shortening cycle melalui sistem neuromuskuler [22]. Plyometric training digambarkan sebagai "reactive neuromuscular training" karena meningkatkan rangsangan reseptor neurologis dan meningkatkan reakktivitas sistem neuromuskuler [23]. Plyometric training dapat memperbaiki elastisitas 
otot yang disebabkan karena menurunnya sensitivitas golgi tendon organ melalui adaptasi pada latihan stretch shortening cycle yang memungkinkan komponen elastisitas otot untuk mentoleransi peregangan yang lebih besar [24]. Penelitian sebelumnya plyometric training dapat meningkatkan kontrol postural dan stabiliasi dinamis, sehingga mengurangi cedera lutut dan mengurangi resiko cedera dengan meningkatkan stabilisasi sendi pada tungkai bawah [25].

Berdasarkan uraian di atas maka dilakukan penelitian dengan tujuan untuk membandingkan kombinasi plyometric training dengan Mobilization with Movement (MWM) dan kombinasi plyometric training dengan Strain Counter Strain (SCS) terhadap peningkatan keseimbangan, Range of Motion (ROM), dan fungsional ankle pada kasus CAI.

\section{METODE}

\section{Rancangan Penelitian}

Penelitian ini merupakan penelitian eksperimental dengan rancangan penelitian pretest and post-test group design. Terdiri dari 2 kelompok, kelompok 1 dengan perlakuan plyometric training dengan mobilization with movement dan kelompok 2 dengan perlakuan plyometric training dengan strain counterstrain. Latihan diberikan 3x seminggu selama 6 minggu.

\section{Tempat dan Waktu Penelitian}

Penelitian ini dilakukan di Klinik Barito Farma, Banjarmasin, Kalimantan Selatan. Waktu penelitian ini dilaksanakan dari bulan Februari April 2019.

\section{Populasi dan Sampel}

Sampel berjumlah 22 orang dengan riwayat cedera sprain ankle lateral minimal 2 kali dan waktu minimal 2 bulan yang lalu, usia 15-27 tahun, nilai SEBT kurang dari 90 dan nilai DFROM kurang dari $10 \mathrm{~cm}$. Kriteria eksklusi adanya riwayat fraktur, post-op ankle, gangguan keseimbangan akibat patologi vestibular, dan/atau gangguan sistem saraf pusat.

\section{Variabel dan Instrumen Penelitian}

Strain counterstrain dilakukan dengan penekanan pada trigger point pada batas nyeri selama 60 detik dan dilakukan 3 repetisi [19]. Mobilization with movement dilakukan dengan posisi sampel berdiri pada lutut dengan ankle yang mengalami cedera sebagai support. Rigid belt dipasang pada tendon Achilles, pasien diminta melakukan gerakan fleksi knee dengan dorsal fleksi ankle [21]. Box jump merupakan salah satu latihan plyometric, gerakan tersebut diawali dengan posisi berdiri pada dua kaki selebar bahu dengan menghadap ke depan box, kemudian dengan melompat ke atas box dan mendaratkan kedua kaki di atas box [24]. Weight-bearing ankle DFROM adalah pengukuran ROM Dorsalfleksi ankle joint dengan menggunakan teknik knee to wall. Pasien berdiri di depan dinding lalu lutut pasien fleksikan sampai menyentuh dinding hingga maksimal dengan tumit tidak berpindah, hitung jarak antara phalange I dengan dinding $(\mathrm{cm})$, sampel menjalani tes 3 kali dan dihitung reratanya [11]. SEBT merupakan tes dinamik yang digunakan untuk menghitung keseimbangan dinamis. Tujuan dari SEBT adalah untuk mencapai jarak sejauh mungkin dengan satu kaki dengan 3 arah yaitu, Anterior (A), Posterolateral (PL), dan Posteromedial (PM). Nilai SEBT akan diubah ke nilai persentase dari panjang tungkai yang diukur dari spina illiaca anterior superior ke distal sampai malleolus medial [16]. FAAM merupakan kuesioner dengan 21 item untuk activity of daily living subscale dan 8 item untuk sport subscale, 
Hamzah. A., Fauziah. E. \& Sa'idah M

Fisiomu. 2020 Vol 1(2):59-67

DOI : $10.23917 /$ fisiomu.v\%vi\%i.10702

dengan skor total untuk activity of daily living subscale adalah 84 dan untuk sport subscale adalah 32. Total skor akan diubah ke nilai persentase (0-100\%) [26].

\section{HASIL DAN PEMBAHASAN}

Hasil

Karakteristik Subjek Penelitian

Table 1. Data Karakteristik Subjek

\begin{tabular}{cccc}
\hline Variabel & $\begin{array}{c}\text { Rerata } \\
\pm \text { SB }\end{array}$ & $\begin{array}{c}\text { Rerata } \\
\pm \text { SB }\end{array}$ & $p$ \\
\hline & $\begin{array}{c}\text { Kelom } \\
\text { pok 1 }\end{array}$ & $\begin{array}{c}\text { Kelom } \\
\text { pok 2 }\end{array}$ & \\
\hline & $21 \pm 3,746$ & $21,909 \pm 4,523$ & 0,621 \\
\hline Umur (th) & & & \\
\hline $\begin{array}{c}\text { Indeks } \\
\text { Massa }\end{array}$ & $20,24 \pm 1,989$ & $20,2 \pm 2,957$ & 0,756 \\
\hline $\begin{array}{c}\text { Wabuh } \\
\text { riwayat } \\
\text { (bln) }\end{array}$ & $3,454 \pm 0,522$ & $3,636 \pm 0,504$ & 0,635 \\
\hline
\end{tabular}

Berdasarkan Tabel 1 diketahui rerata umur subjek dalam penelitian ini adalah $21 \pm 3,746$ tahun pada

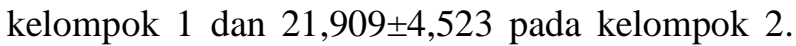
Didapatkan rerata indeks massa tubuh subjek adalah 20,24 $\pm 1,989$ dan 20,2 $\pm 2,957$ pada kelompok 2, rerata tersebut masuk daam kataegori ideal. Hasil uji kemaknaan ketiga variable tersebut tidak mempunyai perbedaan yang signifikan antara kelompok 1 dan kelompok 2. Hal ini menunjukan bahwa kedua kelompok meiliki karakteristik umur, indeks massa tubuh dan waktu riwayat yang sama.

Berdasarkan tabel 2 tersebut dapat diuraikan bahwa tidak ada perbedaan yang signifikan antara data pada kelompok 1 dan kelompok 2 ( $p>0,05)$. Hal ini menyatakan bahwa kondisi data awal subjek sama antara kelompok 1 dan kelompok 2, dengan demikian maka efek intervensi murni terjadi akibat perlakuan.

Tabel 2. Hasil Uji Komparabilitas pre Kelompok 1 dan Kelompok 2

\begin{tabular}{ccc} 
Variabel & Rerata \pm SB & $p$ \\
\hline DFROM pre Kel 1 & $6,36 \pm 1,120$ & 0,157 \\
DFROM pre Kel 2 & $6,45 \pm 1,035$ & \\
SEBT A pre Kel 1 & $75,09 \pm 1,300$ & \\
SEBT A pre Kel 2 & $75,36 \pm 1,206$ & 0,160 \\
SEBT PL pre Kel 1 & $80,90 \pm 1,136$ & \\
SEBT PL pre Kel 2 & $80,18 \pm 0,873$ & 0,187 \\
SEBT PM pre Kel 1 & $81,54 \pm 1,368$ & \\
SEBT PM pre Kel 2 & $81,18 \pm 1,167$ & 0,152 \\
FAAM (ADL) pre Kel & $89,30 \pm 0,693$ & \\
1 & \\
FAAM (ADL) pre Kel & $88,92 \pm 0,562$ & 0,135 \\
2 & \\
FAAM (sport) pre Kel & $74,42 \pm 1,533$ & \\
1 & \\
FAAM (sport) pre Kel & $74,2 \pm 1,548$ & 0,148 \\
2 &
\end{tabular}

\section{Efek Perlakuan}

\section{Tabel 3. Hasil Uji Efek Perlakuan Kelompok 1}

\begin{tabular}{ccc} 
Variabel & Rerata \pm SB & $p$ \\
\hline DFROM pre & $6,36 \pm 1,120$ & 0,001 \\
DFROM post & $12,18 \pm 1,677$ & \\
SEBT A pre & $75,09 \pm 1,300$ & 0,001 \\
SEBT A post & $87,63 \pm 1,501$ & \\
SEBT PL pre & $80,9 \pm 1,136$ & 0,001 \\
SEBT PL post & $84,09 \pm 0,301$ & \\
SEBT PM pre & $81,54 \pm 1,368$ & 0,001 \\
SEBT PM post & $86,36 \pm 1,120$ & \\
FAAM (ADL) pre & $89,3 \pm 0,693$ & 0,001 \\
FAAM (ADL) post & $91,3 \pm 1,232$ & \\
FAAM (sport) pre & $74,42 \pm 1,533$ & 0,001 \\
\end{tabular}


FAAM (sport) post

$88,30 \pm 0,997$

Hasil uji efek perlakuan kelompok 1 seperti yang tampak pada tabel 3 di atas menunjukkan bahwa semua variabel terdapat perbedaan yang signifikan antara pre dan post perlakuan pada kelompok 1 $(p<0,05)$. Hal ini menyatakan bahwa kombinasi plyometric training dengan MWM dapat meningkatkan ROM ankle joint, keseimbangan, dan fungsional ankle joint.

Tabel 4 Hasil Uji Efek Perlakuan Kelompok 2

\begin{tabular}{ccc}
\hline Variabel & Rerata \pm SB & $p$ \\
\hline DFROM pre & $6,45 \pm 1,035$ & 0,001 \\
DFROM post & $8,90 \pm 1,004$ & \\
SEBT A pre & $75,36 \pm 1,206$ & 0,001 \\
SEBT A post & $84,63 \pm 0,504$ & \\
SEBT PL pre & $80,18 \pm 0,873$ & 0,001 \\
SEBT PL post & $82,36 \pm 1,026$ & \\
SEBT PM pre & $81,18 \pm 1,167$ & 0,001 \\
SEBT PM post & $84,81 \pm 0,603$ & \\
FAAM (ADL) pre & $88,92 \pm 0,562$ & 0,001 \\
FAAM (ADL) post & $90,98 \pm 1,292$ & \\
FAAM (sport) pre & $74,2 \pm 1,548$ & 0,001 \\
FAAM (sport) post & $88,09 \pm 0,935$ & \\
\hline
\end{tabular}

Berdasarkan tabel 4 tersebut dapat diuraikan bahwa ada perbedaan yang signifikan antara data pada kelompok 1 dan kelompok 2 ( $p>0,05)$, tetapi tidak pada FAAM ( $>>0,05)$. Hal ini menyatakan bahwa kombinasi plyometric training dengan MWM lebih baik dibanding kombinasi plyometric training dengan SCS dalam meningkatkan ROM ankle joint dan keseimbangan.

\section{Pembahasan}

Teori proprioseptif dari SCS menunjukkan bahwa sprain injury dapat menyebabkan ketidakseimbangan dalam stretch reflex monosinaptik, di mana mekanisme muscle spindle dari gerakan inversi ankle dalam keadaan hiperaktif dan dengan keadaan hipersensitif [27]. Howell et all, telah mendukung teori Korrs bahwa SCS mengarah pada pengurangan mekanisme peregangan hiperaktif yang terjadi setelah sprain injury[28]. Respons refleks otot-otot ankle yang menurun dapat dijelaskan lebih lanjut oleh penghambatan timbal balik yang disebabkan oleh hiperaktif inversi ankle. Penghambatan eversi ini dapat membuat otot-otot ankle tidak efisien dalam kemampuannya untuk melindungi ankle dari gerakan inversi yang mengakibatkan sprain ankle berulang. Teori ini didukung oleh kesimpulan Wikstrom et all. Bahwa seorang dengan CAI memiliki perubahan dalam mekanisme feedforward and feedback pada gait cycle. SCS menyebabkan stretch reflex pada otot-otot inversi ankle menjadi normal, sehingga memperbaiki neuromuskuler dan fungsi sendi ankle [29].

Pasien dengan CAI mengalami keterbatasan pada DFROM yang dapat dikaitkan denan ganngguan fungsional seperti perubahan sensorimotor dan perasaan subjektif "tidak stabil" Denegar et al mengemukakan bahwa adanya keterbatasan pada posterior talar glide yang menyebabkan terbatasnya ROM ankle sagital setelah sprain ankle [30]. Keterbatasan pada posterior talar glide dalam jangka panjang akan menyebabkan cedera berulang [31]. DFROM berpengaruh terhadap arthrokinematik ankle joint yang menyampaikan informasi afferent untuk sensorymotor system [11]. Oleh karena itu, perbaikan DFROM menjadi prioritas pada kasus CAI. Peran subtalar joint dalam arthrokinematik ankle joint dianggap sebagai faktor yang mempengaruhi gangguan fungsional dan sensorymotor system [31], sehingga ada kemungkinan bahwa mobilisasi sendi dapat 
mengembalikan ROM sendi normal dan memperbaiki penyampaian informasi afferent serta perubahan proprioseptif. Teknik manual terapi (secara umum) telah menunjukkan efek biomekanik dalam penelitian untuk meningkatkan ROM [32]. Beberapa penelitian menyarankan kombinasi antara terapi latihan dan manual terapi untuk meningkatkan ROM [33]. Dua artikel menyatakan bahwa terapi manual MWM memberikan peningkatakan yang signifikan terhadap DFROM ankle joint [34,35]. Kelebihan MWM yaitu bentuk mobilisasi sendi dengan pasien yang aktif bergerak, sementara fisioterapis melakukan mobilisasi sendi, tidak seperti mobilisasi sendi lain yang mengharuskan fisioterapis secara pasif memanipulasi sendi pasien [21]. Penelitian lebih lanjut diperlukan untuk menganalisis efek jangka panjang MWM pada CAI.

\section{KESIMPULAN}

Berdasarkan hasil analisis dan pembahasan yang telah dijabarkan sebelumnya, dapat disimpulkan bahwa.

1. Kombinasi plyometric training dengan Strain Counter Strain (SCS) dapat meningkatan keseimbangan, Range of Motion (ROM), dan fungsional ankle pada kasus CAI.

2. Kombinasi plyometric training dengan Mobilization With Movement (MWM) dapat meningkatkan keseimbangan, Range of Motion (ROM), dan fungsional ankle pada kasus CAI.

3. Kombinasi plyometric training dengan Mobilization With Movement (MWM) lebih baik disbanding kombinasi plyometric training dengan Strain Counter Strain (SCS) dalam meningkatkan keseimbangan, Range of Motion (ROM), dan fungsional ankle pada kasus CAI.

\section{DAFTAR PUSTAKA}

1. Fong DT, Hong Y, Chan LK. A systematic review on ankle injury and ankle sprain in sports. Sports Med. 2007; 37(1): 73-94.

2. Waterman BR, Owens BD, Davey S, Belmonnt PJ. The epidemiology of ankle sprains in the United States. J Bone Joint Surg Am. 2010;92:2279-84.

3. Gribble PA, Bleakley CM, Caulfi eld BM. Evidence review for the 2016 International Ankle Consortium consensus statement on the prevalence, impact and long-term consequences of lateral ankle sprains. $\mathrm{Br} \mathrm{J}$ Sports Med. 2016; 50(24): 1496-1505.

4. Hiller CE, Kilbreath SL, Refshauge KM. Chronic ankle instability: evolution of the model. J Athl Train. 2011;46:133-41.

5. Hertel J. Functional anatomy, pathomechanics, and pathophysiology of lateral ankle instability. J Athl Train. 2002;37:364-75.

6. Hubbard TJ, Hertel J. Mechanical contributions to chronic lateral ankle instability. Sports Med. 2006;36:263-77.

7. McKeon PO, Hertel J. Systematic review of postural control and lateral ankle instability: part 1. Can deficits be detected with instrumented testing? J Athl Train. 2008;43:293-304.

8. Terada M1, Pietrosimone BG, Gribble PA. Therapeutic interventions for increasing ankle dorsiflexion after ankle sprain: $a$ systematic review. J Athl Train. 2013;48:696-709.

9. Holmes A, Delahunt E. Treatment of common deficits associated with chronic ankle instability. Sports Med. 2009;39:20724.

10. Klykken LW, Pietrosimone BG, Kim Km, Ingersoll CD. Motor-neuron pool excitability of lower leg muscle after acute lateral ankle sprain. J Athl Train. 2011;46:263-9.

11. Hoch MC, Staton GS, Medina McKeon JM. Dorsiflexion and dynamic postural control deficits are present in those with chronic ankle instability. J Sci Med Sport. 2012;15:574-9. 
Hamzah. A., Fauziah. E. \& Sa'idah M

Fisiomu. 2020 Vol 1(2):59-67

DOI : $10.23917 /$ fisiomu.v\%vi\%i.10702

12. Johanson $\mathrm{M}$, Baer J, Hovermale $\mathrm{H}$, Phouthavong P. Subtalar joint position during gastrocnemius stretching and ankle dorsiflexion range of motion. $\mathrm{J}$ Athl Train. 2008;43:172-8.

13. Diaz DC, Rafael LV, Maria CP, Fidel HC, Antonio MA. Effects of joint mobilization on chronic ankle instability: a randomized controlled trial. Disabil Rehabil J. 2014;1:110.

14. Hertel J. Sensorimotor deficits with ankle sprains and chronic ankle instability. Clin Sports Med. 2008;27:353-70.

15. van Rijn RM, van Os AG, Bernsen RMD. What is the clinical course of acute ankle sprains? A systematic literature review. Am J Med. 2008;121:324-31.

16. Gribble PA, Hertel J, Denegar CR, Buckley WE. The effect of fatigue and chronic ankle instability on dynamic postural control. J Athl Train. 2004;39:321-9.

17. Carter C, Micheli L. Training the child athlete: physical fitness, health and injury. $\mathrm{Br}$ J Sports Med. 2011;45:880-885.

18. Wong CK. Strain counterstrain: current concepts and clinical evidence. Man Ther. 2012;17:2-8.

19. Colliins CK, Michael M, Joshua AC. The effectiveness of strain counterstrain in the ankle treatment of patients with chronic ankle instability: A randomized clinical trial. Journal of Manual and Manipulative Therapy. 2014;119-128;22-3

20. Vicenzino B, Prangley I, Martin D. The initial effect of two Mulligan mobilizations with movement treatment techniques on ankle dorsiflexion. Australian Conference of Science and Medicine in Sport. Sports Medicine Australia; 2001

21. Hoch MC, Anreatta RD, Mullineaux DR. Two week joint mobilization intervention improves self-reported function, range of motion, and dynamic balance in those with chronic ankle instability. J Orthop. 2010;30:1798-804.
22. Toumi H, Best TM, Martin A, F'Guyer S, Poumarat G. Effects of eccentric phase velocity of plyometric training on the vertical jump. J Sports Med. 2004;25(5):391-398.

23. Komi PV, Hoboken NJ. Strength and Power (Stretch-shortening cycle. Blackwell Science. 2003:184-202.

24. McGuine TA, Keene JS. The effect of a balance training program on the risk of ankle sprains in high school athletes. J Sports Med. 2006;34(7):1103-1111.

25. Kubo K, Morimoto M, Komuro T. Effects of plyometric and weight training on muscletendon complex and jump performance. Med Sci Sports Exerc. 2007;39(10):1801-1810.

26. Martin RL, Irrgang JJ, Burdett RG, Conti SF, Van Swearingen JM. Evidence of validity for the foot and ankle ability measure (FAAM). Foot Ankle Int. 2005;26:968-83.

27. Mattacola CG, Dwyer MK. Rehabilitation of the ankle after acute sprain or chronic instability. J Athl Train. 2002;37:413-29.

28. Howell JN, Cabell KS, Chila AG, Eland DC. Stretch reflex and Hoffmann reflex responses to osteopathic manipulative treatment in subjects with Achilles tendinitis. J Am Osteopath Assoc. 2006;106:537-45.

29. Wikstrom EA, Bishop MD, Inamdar AD, Hass CJ. Gait termination control strategies are altered in chronic ankle instability subjects. Med Sci Sports Exerc. 2010;42:197-205

30. Denegar CR, Hertel J, Fonseca J. The effect of lateral ankle sprain on dorsiflexion range of motion, posterior talar glide, and joint laxity. J Orthop Sports Phys Ther. 2002;32:166-73.

31. Pellow JE, Brantingham JW. The efficacy of adjusting the ankle in the treatment of subacute and chronic grade I and grade II ankle inversion sprains. J Manip Physiol Ther. 2001;24:17-24.

32. Hsieh CY, Vicenzino B, Yang CH. Mulligan's mobilization with movement for the thumb: a single case report using magnetic resonance imaging to evaluate the 
Hamzah. A., Fauziah. E. \& Sa'idah M

Fisiomu. 2020 Vol 1(2):59-67

DOI : $10.23917 /$ fisiomu.v\%vi\%i.10702

positional fault hypothesis. Man Ther. 2002;7:44-9.

33. Abbott JH, Robertson MC, Chapple C. Manual therapy, exercise therapy, or both, in addition to usual care, for osteoarthritis of the hip or knee: a randomized controlled trial. Man Ther. 2013;21:525-34.

34. Reid A, Birmingham TB, Alcock G. Efficacy of mobilization with movement for patients with limited dorsiflexion after ankle sprain: a crossover trial. Physio Can. 2007;59:166-72. 35. Collins N, Teys P, Vicenzino B. The initial effects of a Mulligan's mobilization with movement technique on dorsiflexion and pain in subacute ankle sprain. Man Ther 2004;9:77-82. 